\title{
FasyChair Preprint
}

\section{Study on Cool Chair equipped with warming function}

Jun Koyama, Yusuke Doi, Masanari Ukai and Tatsuo Nobe

EasyChair preprints are intended for rapid dissemination of research results and are integrated with the rest of EasyChair.

April 6, 2019 


\title{
Study on Cool Chair equipped with warming function
}

\author{
Jun Koyama ${ }^{1}$, Yusuke Doi ${ }^{1}$, Masanari Ukai $^{2}$, and Tatsuo Nobe ${ }^{1}$ \\ ${ }^{1}$ Kogakuin University, Tokyo, Japan \\ ${ }^{2}$ Waseda University, Tokyo, Japan
}

\begin{abstract}
Recent air-conditioning systems aim to provide thermal comfort for an unspecified number of residents. However, office workers may perceive the feeling of comfort differently depending on their clothing, metabolic rate, and personal activity level. This may cause difficulties in maintaining an optimal thermal environment. To address this problem, personal air-conditioning has attracted attention, which is highly versatile and can reduce thermal discomfort and provide comfort to all office workers by enabling individual thermal control. Therefore, the authors focused on developing an office chair, the "Cool Chair", as a chair-type personal air-conditioning system with a cooling function from 2003 to 2016. The authors then added a warming function for year-round operation, creating the "Cool Chair with Warming Function" in 2017. Subjective evaluation results are reported. These experiments using the new chair indicated that the warming function achieves steady state in 30 minutes and the equivalent temperature of the entire body increases by $+2^{\circ} \mathrm{C}$. In subject experiments, the warming and cooling functions were adjusted according to individual preferences, and the cooling function was used even during winter by some individuals. The authors also confirmed that the feeling of comfort by the subjects improved at both $19^{\circ} \mathrm{C}$ and $22^{\circ} \mathrm{C}$.
\end{abstract}

\section{Introduction}

\subsection{Background}

Recently, air-conditioning systems, which have uniform temporal and spatial variations for environments, have caught attention. For example, floor flow air-conditioning and radiation air-conditioning have been introduced into many offices. It is thought that the thermal comfort of office workers is improved because these systems can control planar temperature with less cold draft. On the other hand, evaluation of thermal comfort based on conventional indexes involves considering a single person in a room as a representative of a group of people with common characteristics. However, in offices, employees differ in their degrees of comfort based on their attire, physical condition, and activity level. Therefore, even if the indoor thermal environment is categorized as comfortable, workers who are sensitive to cold or heat will presumably complain of discomfort. As a solution to this problem, personal air-conditioning systems have been attracting significant attention as a means of improving the thermal comfort of office workers. With a personal air-conditioning system, each worker can adjust the thermal environment to his or her desired preference.

\subsection{Transition of Cool Chair}

The authors have developed a chair-type personal airconditioning unit, calling it the Cool Chair. Fig. 1 shows the successive development of the Cool Chair. As a background for the development of the chair-type personal air-conditioning, the authors focused on an office chair, which was closest to those typically used by office workers at a major Japanese conglomerate in 2003. Cool Chair 2003 was the first experimental model. This model had four air outlets on the movable armrests, and the air velocity at the body surface of an occupant could be adjusted using a fan speed controller. Air intakes were installed on the seat and backrest of the chair. Air inhaled from the seat and backrest was led through the fan and ducts to the outlets on the armrests [1]. Cool Chair 2004 became cordless, with a DC fan and a lead storage battery [2]. Cool Chair 2010 was a practical model. Cool Chair 2010 had three fans installed on the left and right armrests and on the seat of the chair [3]. With the design change to mesh construction, Cool Chair 2013 had only a single fan under the seat compared with the three fans in the other previous models, and the necessary air volume was considerably reduced [4]. The previous model, Cool Chair 2016, featured improved air volume by returning to a three-fan design, which was further improved by miniaturizing the fans. This model contributed to the improved comfort of users in subject experiments by providing users options for speed and direction of airflow [5]. In this study, the authors report the specifications of the Cool Chair 2017, performance evaluation of the Cool Chair 2017 by utilizing a thermal manikin, and evaluation of real-world operation situation of this chair by a human subject experiment. Additionally, the operation evaluation of the cooling function was carried out in the summer of 2016 [6].

*Corresponding author:dm18025@ns.kogakuin.ac.jp 
2003 Model
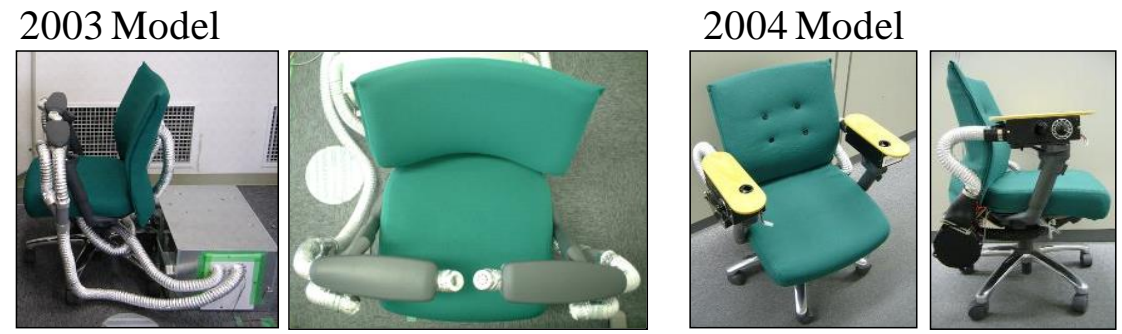

2010 Model

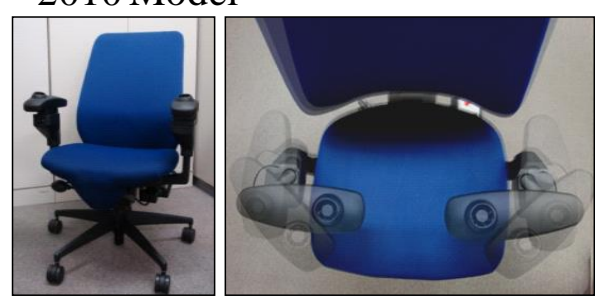

2013 Model

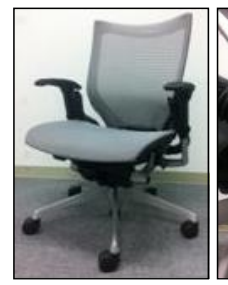

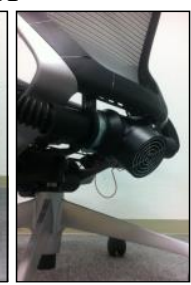

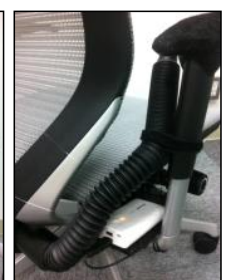

2016 Model

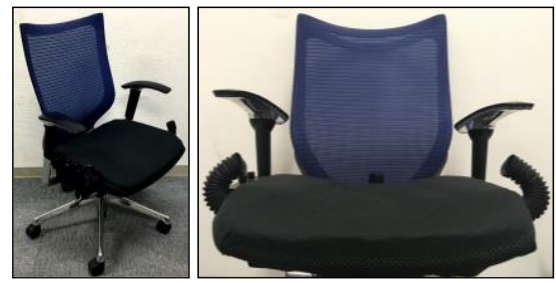

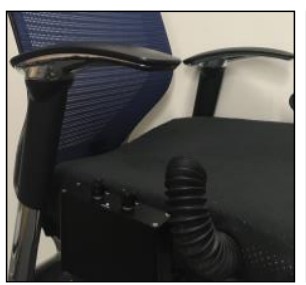

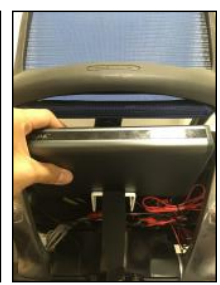

Fig. 1. The successive development of the Cool Chair.

\subsection{Requirements for thermal environment of actual office workers}

Fig. 2 shows the outline of requirements for a comfortable thermal environment. Table 1 shows outline of the authors' investigation. The corresponding paper [7] reported the worker's requirements for the thermal environment in the form of a check sheet that is compiled by the building maintenance managers according to the complaints regarding the thermal environment of the office workers. The authors investigated number of complaints, which included: "Hot", "Cold", "Uncomfortable because of system air-velocity", "Coldness due to air-speed", "Coldness of feet", and "Other". Fig. 3 shows the number of complaints regarding the thermal environment of office workers to the building maintenance managers. The complaints from females accounted for more than $85 \%$ of all complaints. It was confirmed that a male requested a change of thermal environment 0.01 times per year on average and a female requested the change of thermal environment 0.12 times per year on average. The total complaints counted were 691 during the six years from 2000 to 2005. Because these complaints included "Cold" and "Coldness due to air-speed", the authors added a warming function to the Cool Chair 2016 and expected to improve the comfort level especially for female chair users.

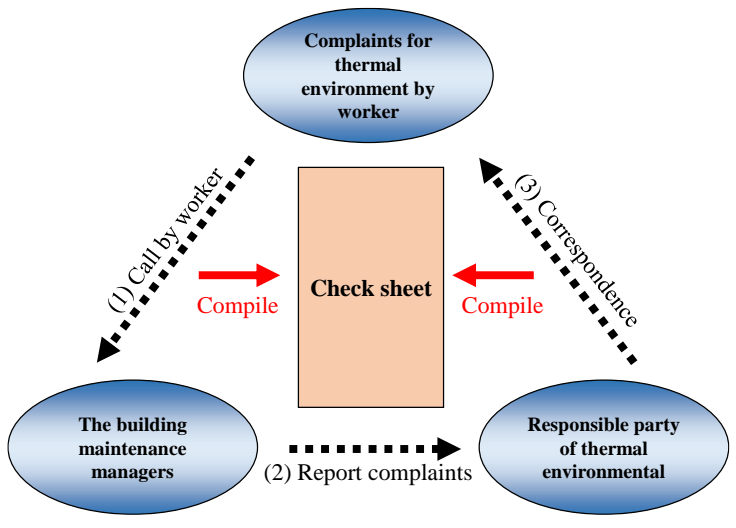

Fig. 2. Outline of complaints regarding the thermal environment.
Table 1. Outline of investigation.

\begin{tabular}{|c|c|}
\hline Place & Minato ward, Tokyo \\
\hline $\begin{array}{c}\text { Architectural } \\
\text { area }\end{array}$ & $27000 \mathrm{~m}^{2}$ \\
\hline $\begin{array}{c}\text { Survey period } \\
\text { Number of } \\
\text { floors }\end{array}$ & 23 floors and 2 basement floors \\
\hline $\begin{array}{c}\text { Air- } \\
\text { conditioning } \\
\text { system }\end{array}$ & Each floor unit CAV + FCU \\
\hline $\begin{array}{c}\text { Declaration } \\
\text { method }\end{array}$ & Air environment check sheet \\
\hline $\begin{array}{c}\text { Declaration } \\
\text { contents }\end{array}$ & Hot, Cold, Uncomfortable by wind, \\
\hline $\begin{array}{c}\text { Coldness by wind, Coldness of feet, Other } \\
\text { Standard floor } \\
\text { plan }\end{array}$ & \begin{tabular}{c} 
and \\
\hline
\end{tabular} \\
\hline
\end{tabular}

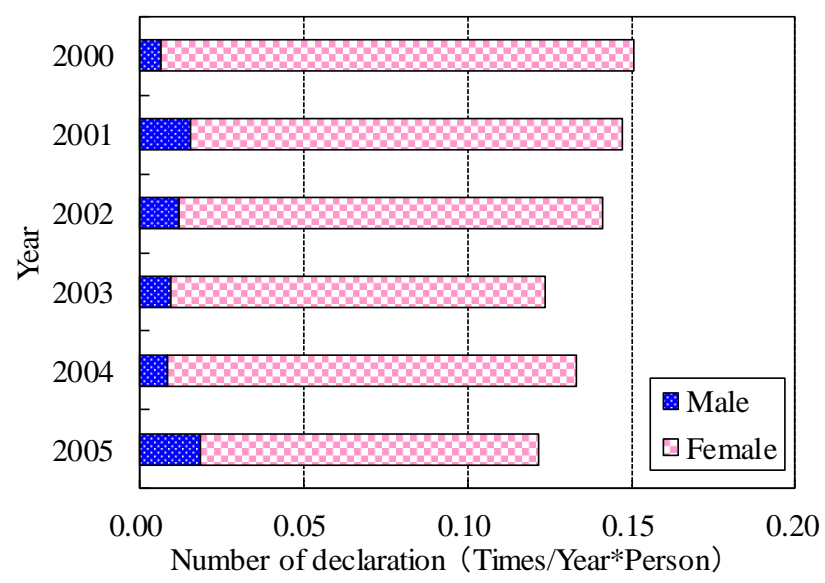

Fig. 3. Number of declarations. 


\section{Specifications of Cool Chair 2017 model}

In the development of the Cool Chair, the authors did not change its function as a chair, but added a cooling function. In this research, the authors added the warming function in addition to the cooling function of the previous model. Table 2 shows the specifications of the Cool Chair 2017.

\subsection{Cooling function}

Three fans are installed inside the seat and a $20-\mathrm{mm}$ threedimensional air-permeable layer covers the seat over the three fans. Air pulled from all over the seat is fed through the fan to flexible hoses, which prevents heat from the human body from building up on the seat. In addition, the Cool Chair 2017 features improved airflow velocity of the fan by $1.6 \mathrm{~m} / \mathrm{s}$ more than the previous model.

\subsection{Warming function}

As a heating device, a linear heater was selected in order to maintain the air-permeability of the seating surface, which is necessary for the cooling function. The linear heating elements are installed in the seat on the back, which enables operating each output individually. In order to prevent overheating, a thermal fuse is wired in the liner heater at the seat and the back. This thermal fuse reacts at $72{ }^{\circ} \mathrm{C}$, and when the temperature exceeds this value, the heater stops working. Fig. 4 shows thermal imaging of the liner heating elements. The liner heater of Cool Chair 2017 reaches $40.5{ }^{\circ} \mathrm{C}$ at the maximum output. Although there are many studies about low temperature burns, it is thought that these do not occur at a surface temperature of $40.5^{\circ} \mathrm{C}[8]$.

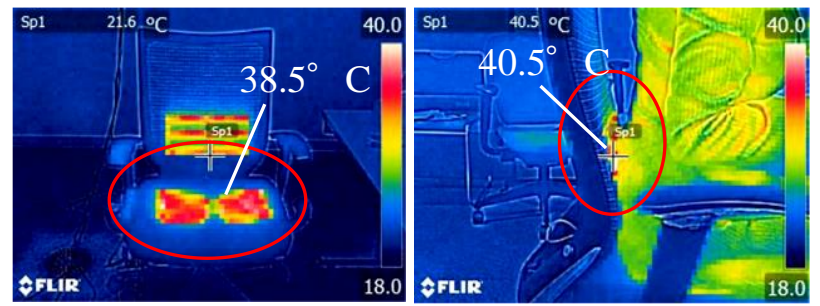

Fig. 4. Thermal image of liner heater.

\subsection{Control and operating method}

The air flow volume can be gradually adjusted using a dial attached to the right side of the seat. The air flow volume at the side and back can be individually controlled using a no-step dial. The control method employs pulse width modulation because its energy consumption is superior when low air volume is used. The fans are also automatically stopped by a seat sensor when the user leaves his or her seat with the power supply switched on.

\subsection{Battery}

The battery of the Cool Chair 2017 has a large capacity of $50 \mathrm{Ah}$. When the battery is fully charged, the fan can move air at the maximum output for approximately 55.6 $\mathrm{h}$ and the heater can move air at the maximum output for approximately $26.0 \mathrm{~h}$. Likewise, the controller LED light turns red during operation to prevent malfunction. Moreover, the detachable portion of the battery is placed on the back of the seat in order not to affect the design of the chair.

Table 2. Specifications of the Cool Chair 2017.

\begin{tabular}{|c|c|c|c|}
\hline 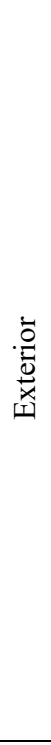 & & & Details of the seat function \\
\hline \multirow{6}{*}{ 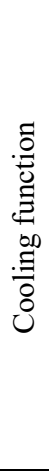 } & \multicolumn{2}{|c|}{ Airflow velocity } & $0-10.8 \mathrm{~m} / \mathrm{s}$ \\
\hline & \multicolumn{2}{|c|}{ Maximum air volume } & $\begin{array}{c}\text { Sum of both sides: } 46.8 \mathrm{~m}^{3} / \mathrm{h} \\
\text { Back: } 23.4 \mathrm{~m}^{3} / \mathrm{h}\end{array}$ \\
\hline & \multicolumn{2}{|c|}{ Air volume control } & No-step dial \\
\hline & \multicolumn{2}{|c|}{ Location of fan } & Inside seat \\
\hline & \multicolumn{2}{|c|}{ Power consumption of fan } & $10.8 \mathrm{~W}$ \\
\hline & \multicolumn{2}{|c|}{$\begin{array}{c}\text { Continuous air-movement } \\
\text { time }\end{array}$} & $55.6 \mathrm{~h}$ \\
\hline \multirow{6}{*}{ 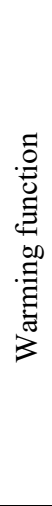 } & \multirow{2}{*}{$\begin{array}{l}\text { Surface } \\
\text { temperature }\end{array}$} & Seat & $28.2-38.5^{\circ} \mathrm{C}$ \\
\hline & & Back & $29.0-40.5^{\circ} \mathrm{C}$ \\
\hline & \multirow{3}{*}{$\begin{array}{l}\text { Linear } \\
\text { heater }\end{array}$} & $\begin{array}{l}\text { Resistance } \\
\text { value }\end{array}$ & $25 \Omega / \mathrm{m}$ \\
\hline & & $\begin{array}{l}\text { Maximum } \\
\text { power }\end{array}$ & Total $23.04 \mathrm{~W}(12 \mathrm{~V})$ \\
\hline & & $\begin{array}{l}\text { Safety } \\
\text { device }\end{array}$ & $\begin{array}{c}\text { Thermal fuse } \\
\text { (Nominal operating } \\
\text { temperature } 72^{\circ} \mathrm{C} \text { ) }\end{array}$ \\
\hline & \multicolumn{2}{|c|}{$\begin{array}{l}\text { Continuous operation } \\
\text { time }\end{array}$} & $26.0 \mathrm{~h}$ \\
\hline \multirow{5}{*}{ 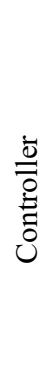 } & \multicolumn{2}{|c|}{$\begin{array}{c}\text { Air volume / } \\
\text { temperature adjustment }\end{array}$} & Stepless variable resistor \\
\hline & \multirow{2}{*}{\multicolumn{2}{|c|}{$\begin{array}{l}\text { Heating / cooling } \\
\text { function management }\end{array}$}} & Changeover switch \\
\hline & & & $\begin{array}{c}\text { LED lamp } \\
\text { (cooling: blue heating: red) }\end{array}$ \\
\hline & \multicolumn{2}{|c|}{ Battery } & $\mathrm{LiB}(12 \mathrm{~V}, 50 \mathrm{Ah})$ \\
\hline & \multicolumn{2}{|c|}{ Operating condition } & Sensor control by sitting \\
\hline
\end{tabular}




\section{Physical performance by thermal manikin evaluation}

\subsection{Outline of evaluation with thermal manikin}

By using a thermal manikin, it is possible to conduct a detailed survey for each body part. In addition, chair performance can be evaluated, such as, heating by contact with a heater or cooling by a fan's airflow. Table 3 shows outline of the survey using thermal manikin. Fig. 5 shows division of each body part. Table 4 shows surface area of each body part. This survey is an experiment assuming winter, and a set temperature of $22{ }^{\circ} \mathrm{C}$. The controller adopted is proportional-integral controller. As actual measurement items, the sensible heat loss and the equivalent temperature for each part of the human body was calculated.

Table 3. Outline of survey with thermal manikin.

\begin{tabular}{|c|c|c|}
\hline \multicolumn{2}{|c|}{ Version } & Manikin version 3.x \\
\hline \multicolumn{2}{|c|}{ Survey period } & January $10-11,2018$ \\
\hline \multirow{4}{*}{ 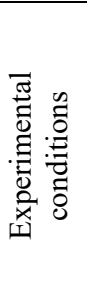 } & $\begin{array}{c}\text { Air } \\
\text { temperature }\end{array}$ & $22{ }^{\circ} \mathrm{C}$ \\
\hline & $\begin{array}{l}\text { Relative } \\
\text { humidity }\end{array}$ & Progress \\
\hline & Air velocity & $0.1 \mathrm{~m} / \mathrm{s}$ \\
\hline & $\begin{array}{c}\text { Average } \\
\text { radiation } \\
\text { temperature }\end{array}$ & Same as air temperature \\
\hline \multirow{3}{*}{ 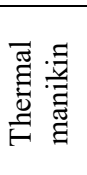 } & Controller & $\begin{array}{l}\text { Proportional-integral controller } \\
\text { (PI mode) }\end{array}$ \\
\hline & Clothes & Suit (1.0 clo) \\
\hline & Posture & Sitting straight \\
\hline
\end{tabular}

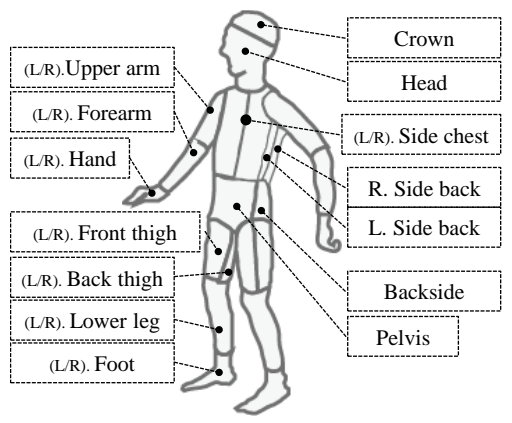

Fig. 5. Division of each body part.

Table 4. Surface area of each body part.

\begin{tabular}{|c|c|c|c|}
\hline Body part & $\begin{array}{c}\text { Surface } \\
\text { area }\left[\mathrm{m}^{2}\right]\end{array}$ & Body part & $\begin{array}{c}\text { Surface } \\
\text { area }\left[\mathrm{m}^{2}\right]\end{array}$ \\
\hline L. Foot & 0.0520 & L. Hand & 0.0435 \\
\hline R. Foot & 0.0520 & R. Hand & 0.0435 \\
\hline L. Lower leg & 0.01140 & L. Fore arm & 0.0409 \\
\hline R. Lower leg & 0.01140 & R. Fore arm & 0.0409 \\
\hline L. Front thigh & 0.0962 & L. Upper arm & 0.0757 \\
\hline R. Front thigh & 0.0962 & R. Upper arm & 0.0757 \\
\hline L. Back thigh & 0.0962 & L. Side chest & 0.0893 \\
\hline R. Back thigh & 0.0962 & R. Side chest & 0.0893 \\
\hline Backside & 0.0736 & L. Side back & 0.0893 \\
\hline Head & 0.0796 & R. Side back & 0.0893 \\
\hline Crown & 0.0524 & All & 1.6447 \\
\hline
\end{tabular}

\subsection{Physical performance with thermal manikin}

\subsubsection{Sensible heat loss amount by thermal manikin}

Fig. 6 shows the sensible heat loss amount of thermal manikin. The sensible heat loss amount in the back thigh and back side was decreased by the heating effect. In addition, it reached a steady state in about 30 minutes. By using the chair's heating function for 30 minutes, the sensible heat loss decreased by $39.1 \mathrm{~W} / \mathrm{m}^{2}$ in the back thigh, $18.8 \mathrm{~W} / \mathrm{m}^{2}$ in the back side, and $7.0 \mathrm{~W} / \mathrm{m}^{2}$ in the whole body.

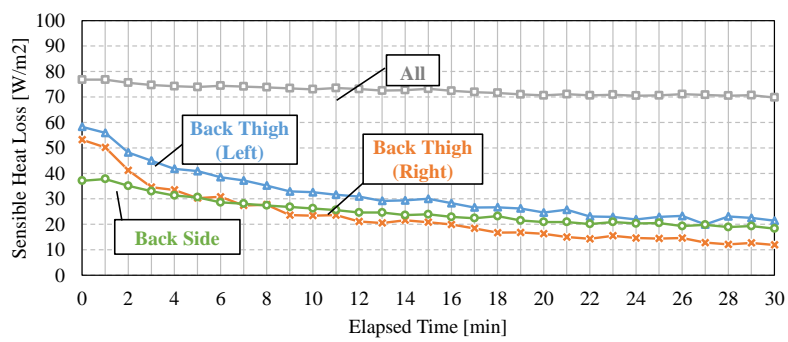

Fig. 6. Sensible heat loss amount by thermal manikin.

\subsubsection{Equivalent temperature by thermal manikin}

Fig. 7 shows the equivalent temperature. In the case of heating only, the equivalent temperature increased by about $+15^{\circ} \mathrm{C}$ in the back thigh and $+2{ }^{\circ} \mathrm{C}$ in whole body. When adding a blanket on knees, the equivalent temperature increased by about $+2{ }^{\circ} \mathrm{C}$ more than the case of heating only.

With regard to the whole-body,

$$
t_{e q}=t_{\mathrm{s}}-\left(I_{c l}+\frac{I_{a}}{f_{c l}}\right)
$$

With regard to each part,

$$
t_{\text {eqi }}=t_{\mathrm{si}}-0.155\left(I_{c l i}+\frac{I_{a i}}{f_{c l i}}\right) \mathrm{Q}_{\mathrm{t}}
$$

where

$t_{e q}=$ equivalent temperature, ${ }^{\circ} \mathrm{C}$

$t_{\mathrm{s}}=$ mean skin temperature, ${ }^{\circ} \mathrm{C}$

$I_{c l}=$ basic clothing insulation, clo

$I_{a}=$ clothing insulation (at nude), clo

$f_{c l}=$ clothing area factor

$t_{\text {eqi }}=$ equivalent temperature of segment, ${ }^{\circ} \mathrm{C}$

$t_{s i}=$ mean skin temperature of segment, ${ }^{\circ} \mathrm{C}$

$I_{c l i}=$ basic clothing insulation of segment, clo

$I_{a i}=$ clothing insulation of segment (at nude), clo

$f_{c l i}=$ clothing area factor of segment

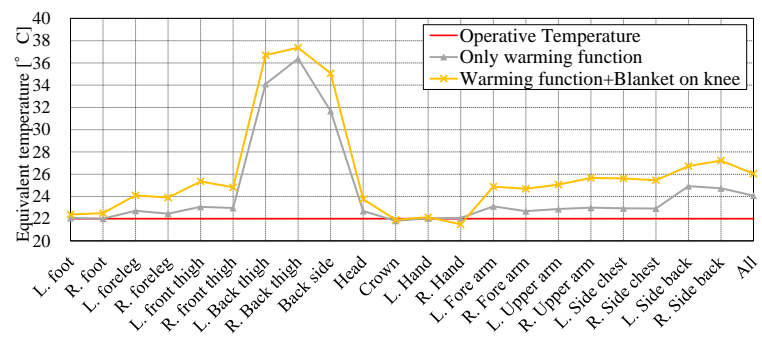

Fig. 7. Equivalent temperature by thermal manikin. 


\section{Subject evaluation}

\subsection{Outline of subject evaluation}

Fig. 8 shows the exterior of the experimental building, Fig. 9 shows the plan of the experimental building, and Table 5 shows the outline of subject evaluation. Subject experiments were verified under two temperature conditions. The first condition was $22{ }^{\circ} \mathrm{C}$, which is the standard set temperature of Japanese offices. The second condition was $19{ }^{\circ} \mathrm{C}$, which is $3{ }^{\circ} \mathrm{C}$ lower in temperature than the first condition. The number of subjects was nine males and ten females. As an activity during the experiment, the subjects played puzzles. They used the general chair and the Cool Chair 2017 Model for each room for 30 minutes. In addition, the subjects were allowed to operate either the cooling function or the warming function when seated in the Cool Chair 2017.

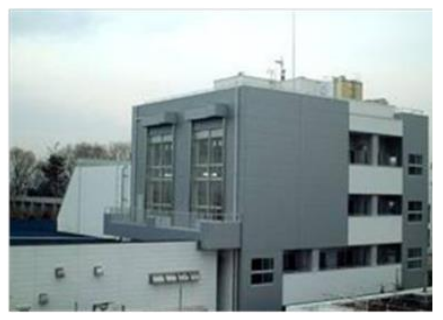

Fig. 8. Exterior of experimental building.

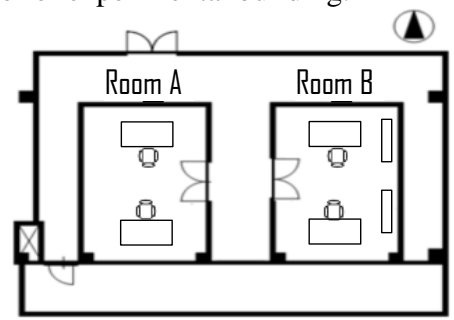

Fig. 9. Plan of experimental building.

Table 5. Outline of subject evaluation.

\begin{tabular}{|c|c|c|}
\hline Place & \multicolumn{2}{|c|}{ Kogakuin Twin Chamber Laboratory } \\
\hline Survey period & \multicolumn{2}{|c|}{ December 4-9, 2017 (6 days) } \\
\hline $\begin{array}{l}\text { Air-conditioning } \\
\text { system }\end{array}$ & \multicolumn{2}{|c|}{ Floor flow, Ceiling suction } \\
\hline $\begin{array}{c}\text { Number of } \\
\text { subjects }\end{array}$ & \multicolumn{2}{|c|}{ Male: 9, Female: 10} \\
\hline Laboratory & A & B \\
\hline Air temperature & $22^{\circ} \mathrm{C}$ & $19^{\circ} \mathrm{C}$ \\
\hline Relative humidity & \multicolumn{2}{|c|}{$50 \%$} \\
\hline Air velocity & \multicolumn{2}{|c|}{$0.1 \mathrm{~m} / \mathrm{s}$} \\
\hline $\begin{array}{c}\text { Average radiation } \\
\text { temperature }\end{array}$ & \multicolumn{2}{|c|}{ Same as air temperature } \\
\hline Clothes & \multicolumn{2}{|c|}{ Male: 1.0 clo, Female: 0.8 clo } \\
\hline Activity & \multicolumn{2}{|c|}{ Puzzle } \\
\hline Metabolic rate & \multicolumn{2}{|c|}{$1.2 \mathrm{Met}$} \\
\hline
\end{tabular}

\subsection{Result of subject evaluation}

\subsubsection{Usage rate of cooling and warming function}

Fig. 10 shows the usage rate of the cooling and warming functions. At 0 minutes elapsed time, the usage rate was low, because the subjects answered the questionnaire. The use of the cooling function was confirmed in subject experiments assumed in winter. Because the cooling function and the warming function were both used, it is thought that the Cool Chair 2017 with the two functions was operated according to the user's feelings of heat and cold.

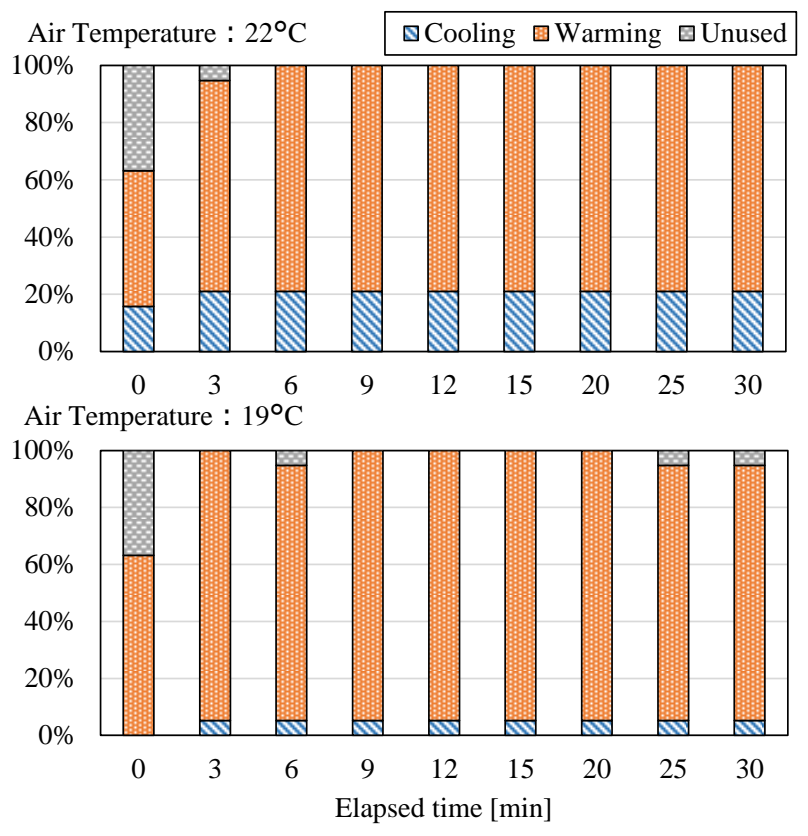

Fig. 10. Usage rate of cooling and warming functions.

\subsubsection{Equivalent cooling and warming temperature}

Fig. 11 shows the equivalent cooling and warming temperature when the subjects used a normal chair and the Cool Chair 2017. The calculation was carried out as follows: a) the subjects were asked to recall their thermal sensation vote (TSV) at three- or five-minute intervals while sitting in both chairs, and b) we calculated the predicted mean vote (PMV) temperature, which has the same value as TSV, and defined the difference between this result and indoor temperature (Room A: $22^{\circ} \mathrm{C}$ Room B: $19{ }^{\circ} \mathrm{C}$ ) as the equivalent cooling and warming temperature. At the temperature setting of $22{ }^{\circ} \mathrm{C}$, the equivalent cooling and warming temperature of the normal chair was identified on the warmer side in males, but females identified the temperatures as cooler. However, equivalent cooling and warming temperature for males changed to a perception of cooler when using the Cool Chair's cooling function. On the other hand, equivalent cooling and warming temperatures for females slowly shifted from the cooler side to the warmer side and rose to about $+0.8^{\circ} \mathrm{C}$ after 30 minutes. When the room temperature setting was $19{ }^{\circ} \mathrm{C}$, the equivalent cooling and

\footnotetext{
* Corresponding author: dm18025@ns.kogakuin.ac.jp
} 
warming temperatures of males and females indicated a perception of cooler temperatures, in particular, females indicated equivalent cooling and warming temperature $2.2{ }^{\circ} \mathrm{C}$ to $-3.5{ }^{\circ} \mathrm{C}$. However, this shifted to a warmer perception after 9 minutes of operation by using the Cool Chair 2017.
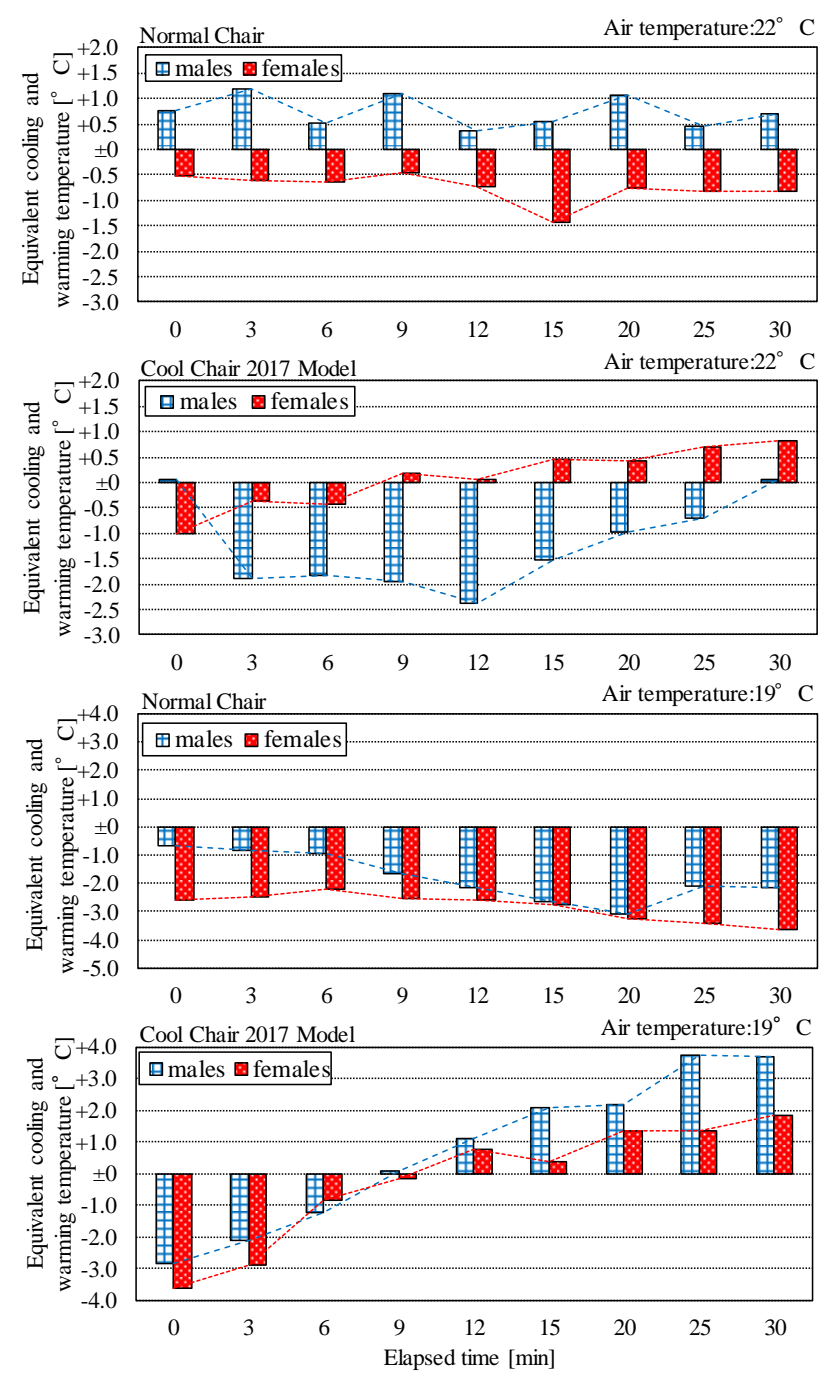

Fig. 11. Equivalent cooling and warming temperatures.

\subsubsection{Evaluation of comfort}

In this study, the authors classified the comfort level by using a questionnaire. Fig. 12 shows the comfort level classifications. The authors divided comfort into three levels and introduced them in a questionnaire, which was answered at three- or five-minute intervals while sitting in the chair. The user who answered uncomfortable at Q.1 is defined as giving an "Uncomfortable" response. For the subjects who answered "Not uncomfortable" at Q.1, it defined their response as "Comfort" for those who answered "Not pleasant" at Q.2. It lastly defined "Pleasantness" [9] for the subjects who answered "Pleasant" at Q.2. Fig. 13 shows the relationship between the comfort level and elapsed time of using a normal chair and the Cool Chair 2017. Under the temperature environment of $22{ }^{\circ} \mathrm{C}$, the normal chair and Cool Chair 2017 have a low rate of "Discomfort", but "Comfort" is replaced by "Pleasantness" when using the Cool Chair 2017. Under the temperature environment of $19^{\circ} \mathrm{C}$, it was not possible to reduce declarations of "Discomfort" by using the Cool Chair 2017. However, it was confirmed that "Comfort" changed to "Pleasantness". These results indicate that the Cool Chair 2017 can change "Comfort" to "Pleasantness" under the two temperature conditions.

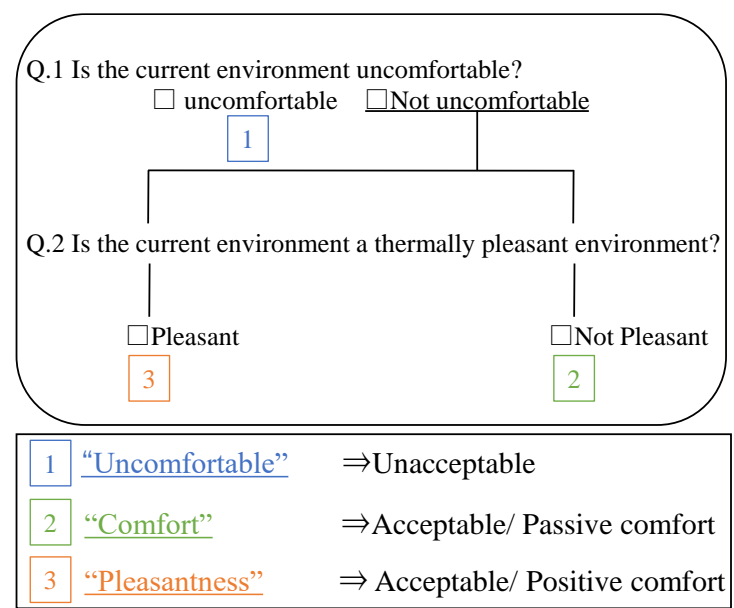

Fig. 12. Classification of comfort levels.

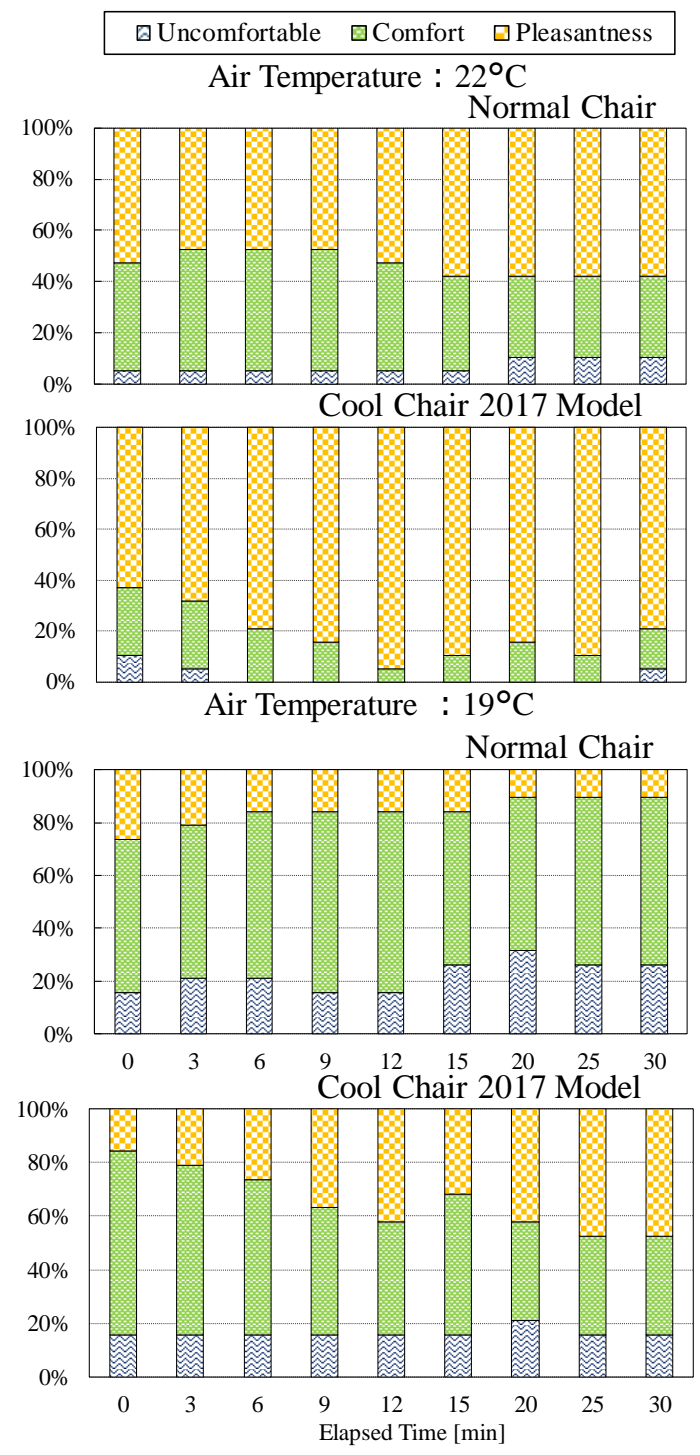

Fig. 13. Relationship between comfort and elapsed time. 


\subsubsection{Overall satisfaction}

Fig. 14 shows the overall user satisfaction for the Cool Chair 2017. It reveals that the subjects, $90 \%$ of men and $80 \%$ of women, responded with feelings of satisfaction in the questionnaire. In addition, no subject answered "Dissatisfaction". Hence, through this subject experiment, it is considered that the Cool Chair 2017 was accepted by the users.

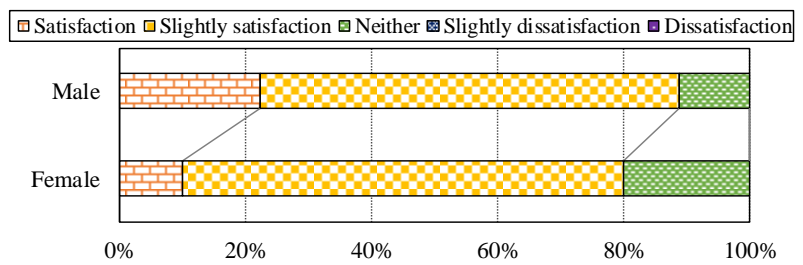

Fig. 14. Overall user satisfaction.

\section{Conclusions}

In this study, the authors evaluated the Cool Chair 2017 by using a thermal manikin and with a subject experiment. The findings are described below.

In a physical performance with thermal manikin, the heating effect of the Cool Chair 2017 has a large influence on the back side to the back thigh and increases the equivalent temperature by $+2.0^{\circ} \mathrm{C}$ in the whole body.

In the subject experiment assumed in the winter, use of the cooling function was confirmed under the temperature environment of $22{ }^{\circ} \mathrm{C}$, especially for the male users. Notably, use of the warming effect by subjects was also confirmed.

It was observed that the overall comfort of the user shifted from "Comfort" to "Pleasantness" when using the Cool Chair 2017. Finally, the overall user satisfaction indicated that more than $80 \%$ of users were satisfied with the Cool Chair 2017.

\section{References}

1. T. Nobe, M. Shoji, S. Shimizu, Roomvent, Coimbra, Portugal (2004)

2. M. Shoji, S. Shimizu, T. Nobe, Summaries of Technical Paper of Annual Meeting Architectural Institute of Japan (2005) (in Japanese)

3. I. Suzuki, K. Washinosu, T. Nobe, Proceedings of the 7th Windsor Conference (2012)

4. M. Ukai, T. Yada, T. Nobe, Roomvent (2014)

5. Y. Doi, M. Ukai, T. Nobe, Roomvent (2018)

6. J. Koyama, Y. Doi, Y. Tanaka, M. Yamada, S. Hanazono, G. Tateyama, M. Ukai, T. Nobe, SHASE (2018) (in Japanese)

7. A. Onga, Y. Iwasa, T. Nobe, SHASE 121151218 (2007) (in Japanese)
8. A.R. Moritz, F.C. Henriques, Am. J. Pathol. 23(5), 695-720 (1947)

9. S. Kuno, H. Ohno, N. Nakahara, ASHRAE Trans. 93, Part 2, 396-406 (1987). 